\title{
Comparing transient and steady-state methods for the thermal conductivity characterization of a borehole heat exchanger field in Bergen, Norway
}

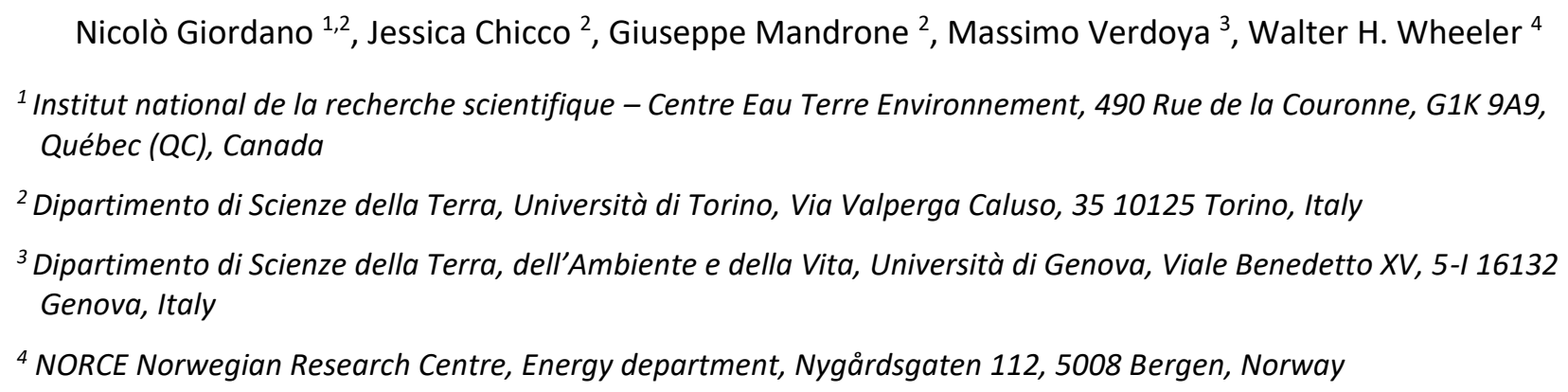

Key words: petrophysical properties, thermal conductivity, P-wave velocity, density, borehole heat exchangers

\section{Abstract}

A comparative study was carried out aiming at characterizing the thermal conductivity of rocks sampled in a borehole heat exchanger field. Twenty-three samples were analysed with four different methods based on both steady-state and transient approaches: transient divided bar (TDB), transient line source (TLS), optical scanning (OS) and guarded hot plate (GHP). Moreover, mineral composition (from XRD analyses), P-wave velocity and density were investigated to assess the petro-physical heterogeneity and to investigate possible causes of divergence between the methods. The results of thermal conductivity showed that TLS systematically underestimates thermal conductivity on rock samples by $10-30 \%$ compared to the other devices. The differences between TDB and OS, and GHP and OS are smaller (about $6 \%$ and $10 \%$, respectively). The average deviation between TDB and GHP, for which the specimen preparation and the measurement procedure was similar, is about $10 \%$. In general, the differences are ascribable to sample preparation, heterogeneity and anisotropy of the rocks, and contact thermal resistance, rather than the intrinsic accuracy of the device. In case of good-quality and homogeneous samples, uncertainty can be as low as $5 \%$, but due to the above mentioned factors usually uncertainty is as large as $10 \%$. Opposite relationships between thermal conductivity and P-wave velocity were observed when 
analysing parallel and perpendicular to the main rock foliation. Perpendicular conductivity values grow with increasing perpendicular sonic velocity, while parallel values exhibit an inverse trend. Thermal conductivity also appears to be inversely correlated to density. In quartz-rich samples, high thermal conductivity and low density were observed. In samples with calcite or other likely dense mineral phases, we noticed that lower thermal conductivity corresponds to higher density. The presence of micas is likely to mask major differences between silicate and carbonate samples.

\section{INTRODUCTION}

The knowledge of the heat transfer processes in the underground is of utmost importance in several fundamental geoscientific topics not only of general interest (e.g. tectonics, basin analysis, etc.), but also in applied research with special reference to geothermal energy. Regarding geothermal applications, in the last 30 years, ground source heat pumps (GSHP) systems have been developing and widely spreading in the framework of the heating and cooling $(\mathrm{H} \& \mathrm{C})$ of the residential, office and commercial buildings. Major numbers are in North America, Europe and China (Lund and Boyd 2015). In 2014, direct uses of geothermal energy in Norway counted an installed capacity of around $1300 \mathrm{MWt}$, an annual energy consumption of $2300 \mathrm{GWh}$ and a load factor of 0.2 (Lund and Boyd 2015). These are mostly related to GSHP, which have increased in number since 2000 (Midtømme et al. 2015), and underground thermal energy storage (UTES; Cabeza 2015). In GSHP and UTES applications, the Earth is exploited for direct use of the heat at accessible depths $(<100 \mathrm{~m})$ by means of either closed-loop borehole heat exchangers (BHE) or open-loop well doublets (e.g. Yang et al. 2010), and as a storage medium for sensible heat applications (e.g. Giordano et al. 2016 and references therein). The performances of BHEs vary significantly depending on the rock type, but also on the presence of groundwater flow which may enhance the heat transfer.

Precise and accurate thermal conductivity measurements of unconsolidated sediments and rocks are crucial for a reliable definition of the heat transfer mechanism within geologic media. Thermal conductivity and specific heat represent the most important properties to describe the mechanism of heat transfer in any material. Studies of the thermo-physical properties of rocks mainly address thermal conductivity because its range of variation is wider than specific heat. Conductivity is primarily controlled by the mineral composition and the texture of the rock. It is generally an anisotropic property, but for many rocks, the effects of anisotropy are minor compared to variations in mineral composition. The bulk value of thermal conductivity generally increases with increasing 
water saturation and density, and decreases with increasing porosity and temperature (Čermák and Rybach 1982; Clauser and Huenges 1995; Alishaev et al. 2012; Mielke et al. 2017). However, correlations between thermal and other properties are not always well defined, mainly due to mineralogical, physical and geochemical factors (Kukkonen and Peltoniemi 1998).

In this paper, we investigate the thermal properties of rocks collected in the area of 200-m-deep BHEs situated south of Bergen, Norway $\left(60.34^{\circ} \mathrm{N}, 5.34^{\circ} \mathrm{E}\right.$; Fig. 1), which has been covering for the 20 years the H\&C needs of a school building (Giordano et al. 2017). In the last years, the heat pumps coefficient of performance has significantly decreased. As a part of the study was therefore necessary to understand the causes of the thermal depletion and to evaluate the sustainable use of the geothermal resource. As a first step of the analysis, here we present results of thermal conductivity measurements of the lithotypes hosting the BHE field.

Over the past 40 years, the necessity of accurate data on both shallow and deep geothermal reservoirs stimulated the development of new effective approaches and equipment for the assessment of thermal conductivity (Pasquale et al. 2015; Popov et al. 2016). In this perspective, comparative studies are important to evaluate the reliability and accuracy of the different methods (e.g. Popov et al. 1999; Zhao et al. 2016) as well as comparisons among the several mixing laws proposed in literature (e.g. Fuchs et al. 2013 and references therein). In this study, we used four different measurement techniques and compared the results in order to evaluate the effects of experimental conditions (e.g. sample preparation, measurement procedure, minimization of thermal contact resistance) and to understand the potential error sources related to the various techniques. In addition, mineral composition, compressional wave velocity and density were detected to investigate the influence of the petro-physical heterogeneity on thermal conductivity and possible causes of divergence in the results of the different techniques adopted.

\section{MATERIALS AND METHODS}

\subsection{Samples and Geological Setting}

This study focuses on 23 samples collected in close $(100-500 \mathrm{~m})$ proximity in a Silurian-aged thrust complex (Fig. 1) on the outskirts of Bergen, Norway. The samples were collected from metric layers analogous to those encountered in the geothermal boreholes. The study area belongs to the Minor Bergen Arc tectonic unit (Proterozoic to Silurian), which together with Øygarden Complex (Proterozoic), Ulriken Gneiss Complex (Proterozoic), Anorthosite Complex (Proterozoic) and the 
Major Bergen Arc (Cambrian to Silurian) form the Bergen Arc System (Kolderup and Kolderup, 1940; Fossen, 1989; Fossen and Ragnhildstveit, 2008; Fig. 1). The Minor Bergen Arc is a strongly deformed continental basement-cover couplet that has been subdivided in the Nordåsvatn Complex, Storetveit Group and Gamlehaugen Complex.

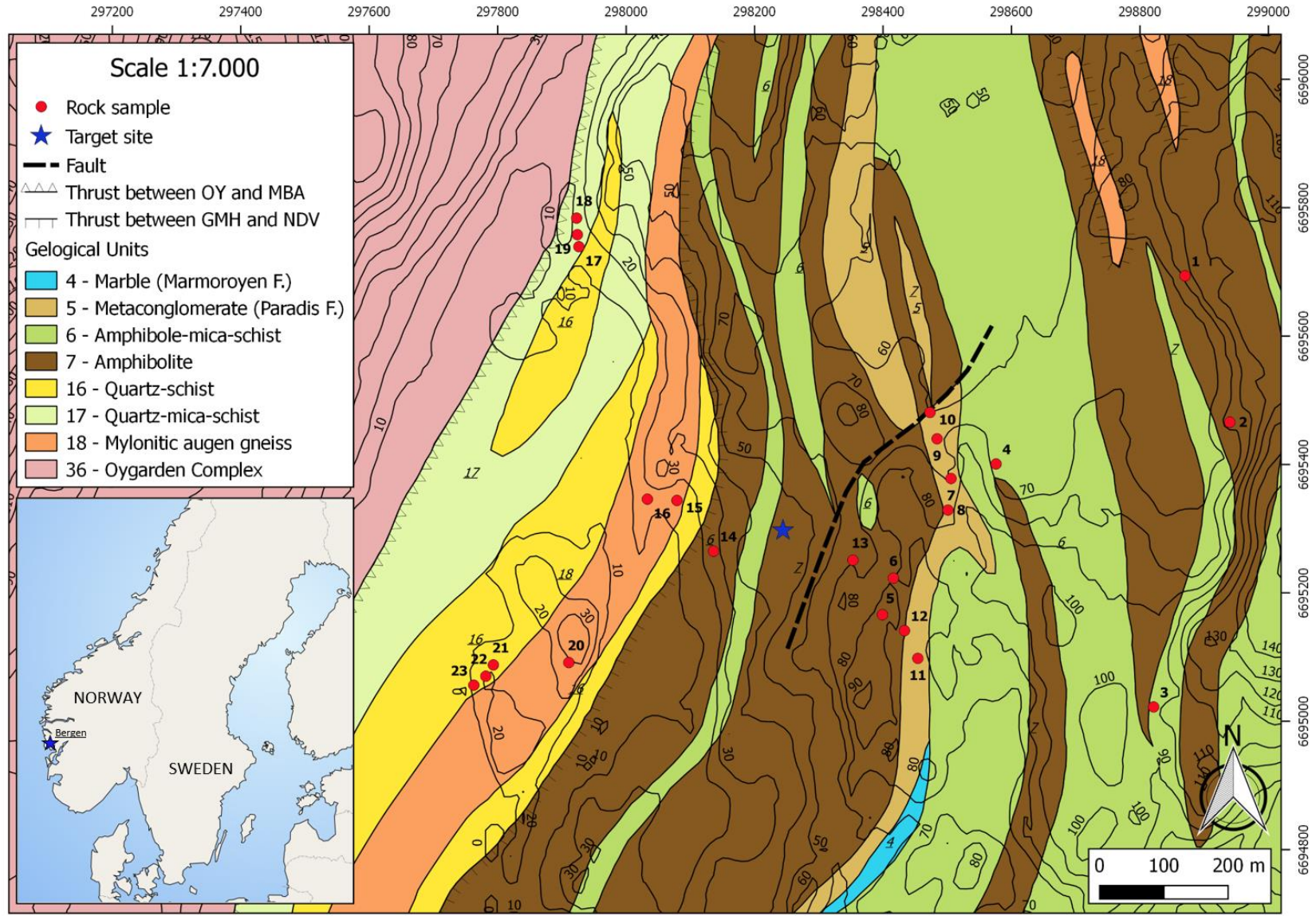

Figure 1 The geological setting of the study area (modified from Fossen and Ragnhildstveit 2008). OY Øygarden Complex, MBA - Minor Bergen Arc, GMH - Gamlehaugen Complex, NDV - Nordåsvatn Complex. Coordinate system WGS84/UTM Zone 32N.

The first is a heterogeneous complex of meta-sedimentary (mafic micaschists with garnet and amphibole in concentrations up to 25\%) and meta-igneous (mainly fine-grained and coarse-grained amphibolites and gabbros; serpentinites in smaller amounts) rocks interpreted as a strongly dismembered ophiolite complex (Fossen 1989 and references therein). An unconformity separates this complex to the supposed younger Storeveit Group, which occurs as a thin (less than $100 \mathrm{~m}$ ) continuous zone within the aforementioned unit and it is made of green metaconglomerates (with 
114 clasts of trondhjemites, amphibolites and epidosites) of the Paradis Formation associated with

115 marbles and calcareous garnet-amphibolite micaschists of the Marmorøyen Formation (Fossen

1161989 and references therein). Finally, the Gamlehaugen Complex groups strongly deformed

117 orthogneisses (proto- to ultra-mylonitic augen gneisses) and metasediments (quartz-schists with

118 abundant presence of mica and feldspar) interpreted as a detached continental basement-cover

119 sequence tectonically emplaced into the Nordåsvatn Complex (Fossen 1989 and references 120 therein).

122 Table 1 List of the collected samples. Acronyms: QMS (quartz-mica-schist); AM (amphibolite); AMS 123 (amphibolite-mica-schist); MB (marble); MS (mica-schist); AG (augen gneiss); QS (quartz-schist).

\begin{tabular}{|c|c|c|c|c|c|}
\hline Number & Lithology & Latitude (N) & Longitude (E) & Description & Geological Unit \\
\hline 1 & QMS & 60.347722 & 5.354263 & Quartz-Mica-schist & \multirow{6}{*}{$\begin{array}{l}\text { Nordåsvatn } \\
\text { Complex }\end{array}$} \\
\hline 2 & AM & 60.345898 & 5.355659 & Amphibolite & \\
\hline 3 & AM & 60.345360 & 5.351639 & Amphibolite & \\
\hline 4 & AM & 60.345000 & 5.349383 & Amphibolite & \\
\hline 5 & AMS & 60.342757 & 5.346535 & Amphibole-mica-schist & \\
\hline 6 & AM & 60.343270 & 5.346782 & Amphibolite & \\
\hline 7 & $\mathrm{MB}$ & 60.344262 & 5.348224 & Marble & \multirow{5}{*}{ Storeveit Group } \\
\hline 8 & $\mathrm{MB}$ & 60.344262 & 5.348224 & Marble & \\
\hline 9 & MB & 60.345252 & 5.347805 & Marble & \\
\hline 10 & $\mathrm{MB}$ & 60.345617 & 5.347565 & Marble & \\
\hline 11 & $\mathrm{MC}$ & 60.342172 & 5.347595 & Meta-conglomerate & \\
\hline 12 & MS & 60.342473 & 5.347279 & Mica-schist & \multirow{3}{*}{$\begin{array}{l}\text { Nordåsvatn } \\
\text { Complex }\end{array}$} \\
\hline 13 & MS & 60.343494 & 5.345621 & Mica-schist & \\
\hline 14 & MS & 60.343512 & 5.341679 & Mica-schist & \\
\hline 15 & QMS & 60.344187 & 5.340576 & Quartz-mica-schist & \multirow{9}{*}{$\begin{array}{l}\text { Gamlehaugen } \\
\text { Complex }\end{array}$} \\
\hline 16 & AG & 60.344180 & 5.339734 & Augen gneiss & \\
\hline 17 & MS & 60.347821 & 5.337358 & Mica-schist & \\
\hline 18 & MS & 60.347821 & 5.337358 & Mica-schist & \\
\hline 19 & MS & 60.347821 & 5.337358 & Mica-schist & \\
\hline 20 & AG & 60.341814 & 5.337834 & Augen gneiss & \\
\hline 21 & QS & 60.340960 & 5.335609 & Quartz-schist & \\
\hline 22 & QS & 60.340960 & 5.335609 & Quartz-schist & \\
\hline 23 & QS & 60.340960 & 5.335609 & Quartz-schist & \\
\hline
\end{tabular}

125 Samples locations were selected according to the surface and depth distribution of the different 126 geological units and to the role of a specific lithotype unit played in the underground thermal and 127 hydraulic regime (Tab. 1). Nine samples belong to the Nordåsvatn Complex (the most representative 
unit), nine to the Gamlehaugen Complex (expected to be the group of rocks with the greatest thermal conductivity) and five specimens were collected in the Storetveit Group (the marble formation expected to play a crucial role in the fluid circulation). Specimens 7-10 of the Storetveit Group are marbles of the Marmorøyen Formation, which crops out in the study area (even if this detail is not shown in Fig. 1, as outcrops are very small and difficult to map).

\subsection{Thermal Conductivity Measurement Techniques}

Four specific devices with different basic principles were used in order to compare the thermal conductivity datasets and discuss the divergence in terms of fundamental theory behind each of them, sample preparation and rock heterogeneity. Measurements were carried out by means of the transient divided bar (TDB) (Pasquale et al. 2015), the transient line source (TLS) (Bristow et al. 1994), the optical scanning (OS) (Popov et al. 2016) and the guarded hot plate (GHP) (Filla 1997). These methods are briefly described in the following together with the specific devices used to perform the measurements.

\subsubsection{Transient Divided Bar (TDB)}

The device includes a stack of elements consisting of two copper blocks of known thermal capacity, between which the studied rock specimen (cylindrical shape) is interposed. The upper block has the same diameter of the specimen and acts as a heat source; the lower block is larger and acts as a heat sink. When the room temperature $T_{0}$ is attained, the lower copper block is plunged into a thermostatic bath with temperature 10 to $15^{\circ} \mathrm{C}$ lower than $T_{0}$. The heat flowing through the sample is equal to the heat adsorbed by the sink and the thermal conductivity can be found by monitoring the temperature changes of the source and the sink (Pasquale et al. 2015). From Fourier's postulate, the amount of heat removed from the upper copper block $C_{u} \Delta T_{u}$ in a given period of time $\Delta t=$ $t_{2}-t_{1}$ is:

$$
C_{u} \cdot \Delta T_{u}=\frac{\lambda S}{h} \int_{t 1}^{t 2}\left(T_{u}-T_{l}\right) d t
$$

where $C_{u}$ is the thermal capacity $\left(\mathrm{J} \mathrm{K}^{-1}\right)$ of the upper block at constant pressure, $\Delta T_{u}\left({ }^{\circ} \mathrm{C}\right)$ the temperature change of the upper block during a time step $d t, \lambda\left(\mathrm{W} \mathrm{m}^{-1} \mathrm{~K}^{-1}\right)$ the thermal conductivity of the rock specimen, $h(\mathrm{~m})$ and $S\left(\mathrm{~m}^{2}\right)$ are the height and the cross-sectional area of the rock sample, 
respectively, $T$ is temperature and the suffixes $u$ and $/$ refer to upper and lower block. The change in temperature is recorded by means of thermocouples connected to a digital acquisition system. During the measurements, the temperature $T_{u}$ and the difference $T_{u}-T_{l}$ are recorded for a period of at least $300 \mathrm{~s}$. Thermal conductivity determinations are carried out at time steps of $10 \mathrm{~s}$ and generally about 10 different time steps are analysed for each sample to obtain an average value. Thermal conductivity can be obtained from:

$$
\lambda=\frac{C_{u} \cdot \Delta T_{u} \cdot h}{S \cdot\left(\overline{T_{u}}-\overline{T_{l}}\right) \cdot \Delta t}
$$

where $\overline{T_{u}}-\bar{T}_{l}$ is the average difference between the values of $T_{u}$ and $T_{l}$ during the time step $\Delta t$. Two correction factors are also taken into account. The first is related to the heat coming from the specimen and therefore an effective heat capacity must be considered, that is the sum of $C_{u}$ and one third of the rock heat capacity (measured by means of a water calorimeter). The second depends on the heat transfer from the surrounding environment to the upper block and can be easily estimated by operating under steady state conditions, i.e. 2 hours after the beginning of the test (Pasquale et al. 2015). The tests were carried out in a temperature-controlled environment at $20^{\circ} \mathrm{C}$ and the thermal conductivity was determined with an accuracy of $\pm 5 \%$.

\subsubsection{Transient Line Source (TLS)}

The line source method is based on the generation of heat at a constant rate by a heated wire. If the line source is assumed to be infinitely long and infinitely thin, fully immersed in an infinite and homogeneous medium, and a recording thermistor is placed in the same probe, the temperature response, in a constant room temperature environment, can be described by:

$$
T_{2}-T_{1}=-\frac{q^{\prime}}{4 \pi \lambda} \cdot \ln \left(\frac{t_{2}}{t_{2}-t_{1}}\right)
$$

where $q^{\prime}\left(\mathrm{W} \mathrm{m}^{-1}\right)$ is the specific rate at which the heat is generated and $T_{1}$ and $T_{2}\left({ }^{\circ} \mathrm{C}\right)$ are the recorded temperatures at time steps $t_{1}$ and $t_{2}(\mathrm{~s})$ respectively. This approximation of the general heat transfer equation of an infinite line source allows for thermal conductivity measurements with errors within $\pm 10 \%$ if the early time data ( $t<200 \mathrm{~s}$ ) are ignored and only the straight line in a graph $\Delta T$ vs $\ln t$ is considered. 
The apparatus adopted in this study is the commercial K2DPro Thermal Property Analyzer

188 (Decagon Devices) that fully complies with the standards ASTM D5334 and IEEE 442 (ASTM, 2014; 189 IEEE, 2003). A proprietary algorithm fits time and temperature data with exponential integral 190 functions using a non-linear least squares method. The single needle sensor RK-1 (length $6 \mathrm{~cm}$, 191 diameter $3.9 \mathrm{~mm}$ ), specific for hard rock samples, was used. A thin hole (4.5 $\mathrm{mm}$ in diameter) was 192 drilled into the sample in order to host the probe and alumina thermal grease $\left(9 \mathrm{~W} \mathrm{~m}^{-1} \mathrm{~K}^{-1}\right)$ was 193 applied to the probe in order to minimize the sensor/rock contact resistance. The measurements 194 were carried out in a controlled room temperature environment and the heating power was about $1956.5 \pm 0.5 \mathrm{~W} \mathrm{~m}^{-1}$ for all the whole set of samples. A $600 \mathrm{~s}$ measuring time was adopted (maximum 196 available) so that $300 \mathrm{~s}$ of heating and $300 \mathrm{~s}$ of cooling were recorded with a $10 \mathrm{~s}$ sampling interval. 197 At least 3 measurements were carried out on each sample and an average was taken. A time 198 interval of $15 \mathrm{~min}$ for each test was adopted in order to allow for the thermal re-equilibrium 199 between the sample and the probe. Before each triplet of measurements, a calibration was 200 performed with the verification standard provided and the calculated calibration factor was 201 applied to correct the thermal conductivity values (ASTM 2014).

\subsubsection{Optical Scanning (OS)}

203 The Optical Scanning is a precision non-contact method designed by Popov et al. (1999). It was 204 developed since the 80s by means of several comparisons with different techniques and calibrated with a number of standard materials (Popov et al. 2016 and references therein). The measurement procedure consists of scanning the sample of a surface with a focused movable heat source (electric lamp) in combination with three infrared temperature sensors (Popov et al. 1999). The heat source and sensors move with the same speed (controllable from 2 to $10 \mathrm{~mm} \mathrm{~s}^{-1}$ ) relative to the sample and at a constant spacing $x_{o}$ among each other (adjustable from 20 to $100 \mathrm{~mm}$ ). Rock samples are placed on a platform in order to be scanned from below by the trolley containing the optical source and the sensors. A synthetic black enamel is applied on the surface in order to neglect the influence of optically transparent surfaces or different minerals' reflectance. The technical parameters of the apparatus adopted in this study are the ones described in Popov et al. 2016 for the Type 1.

The method is based on the heat conduction equation for a quasi-stationary field in a movable coordinate system. The temperature rise induced in the sample and recorded along the scanning line is related to the thermal conductivity as

$$
T_{h}-T_{c}=\frac{q}{2 \pi \cdot x_{0} \cdot \lambda}
$$


218 where $T_{h}$ and $T_{c}\left({ }^{\circ} \mathrm{C}\right)$ are temperatures registered by the hot (after the heating source) and cold 219 (before) sensors, $q(\mathrm{~W})$ is the constant heating power and $x_{o}$ is the distance between the source and 220 the hot sensor. Since the temperature rise depends on both the heating power and the value of $x_{0}$, 221 the measurements are always performed in comparison to standards of known thermal conductivity 222 (e.g. glasses, fused quartz, gabbro etc.). Standards are placed before and after the sample under 223 exam such that they are scanned with the same $q$ and $x_{0}$ and within the same room temperature.

224 In this study, an OS apparatus designed by Lippman and Rauen GbR was used. For all the 225 measurements $q$ was set to about $17 \mathrm{~W}$ (20\% of the maximum power) with a scanning velocity of 5 $226 \mathrm{~mm} \mathrm{~s}^{-1}$ and $x_{0}=50 \mathrm{~mm}$. The standards adopted were homogeneous gabbro samples (provided by 227 the company) with thermal conductivity of $2.37 \mathrm{~W} \mathrm{~m}^{-1} \mathrm{~K}^{-1}$ and the measurements were performed 228 in a controlled temperature environment at around $20^{\circ} \mathrm{C}$. Three runs were carried out per each 229 sample's scanning line and an average was taken. The accuracy certified by the company is $\pm 3 \%$. In 230 case of a sample with a clear two-dimensional anisotropy (e.g. schists), the principal values of the 231 conductivity were determined from two non-collinear scanning lines performed on one face not 232 parallel to the foliation as suggested by Popov et al. 2016. This was done for all the samples in order 233 to check a possible thermal anisotropy even where a clear textural anisotropy was not present (e.g. 234 marbles). An anisotropy factor $K_{T}=\lambda_{\text {par }} / \lambda_{\text {per }}$ was then calculated and the sample was considered 235 thermally homogeneous only in case of $K_{T}<1.1$.

\subsubsection{Guarded Hot Plate (GHP)}

237 The guarded hot plate or heat flow meter is a stationary technique based on standards ASTM C177 238 (2013) and ASTM C518 (2017) that also allows measuring thermal conductivity of semiconductors 239 at high temperatures (Filla 1997). A steady state one-dimensional heat flow is applied through a 240 specimen by two parallel plates guarded at different constant temperatures, while the whole stack 241 is insulated to avoid side heat losses. Temperature and heat flow are continuously registered on 242 both plates throughout the test by means of thermocouples and transducers, while an axial load is 243 provided to minimize the thermal contact resistance.

244 The apparatus adopted in this study is the commercial device Fox50 (LaserComp Inc., 2001-2004). 245 It can measure the thermal conductivity of cylindrical shaped samples, with diameters of $24625 \div 61 \mathrm{~mm}$ and maximum thickness of $25 \mathrm{~mm}$, in the range $-5 \div 185^{\circ} \mathrm{C}$ (Raymond et al. 2017). 247 Proprietary heat flow transducers together with high accuracy $\left( \pm 0.01^{\circ} \mathrm{C}\right)$ type $\mathrm{E}$ thermocouples are 248 bonded and sealed to the surfaces of both plates. Guarded temperature on the heat source (upper 
plate) and sink (lower) are provided by Peltier elements and a downward heat flow is generated through the rock specimen. From the Fourier heat conduction law, the temperature gradient within the sample is given by the difference between the cold and hot plate temperatures divided by the sample thickness. However, for conductivity values $>0.2-0.3 \mathrm{~W} \mathrm{~m}^{-1} \mathrm{~K}^{-1}$ (basically all the rocks and minerals), the temperatures on the sample surfaces are different from the plates because the thermal contact resistance is not significantly smaller than the sample thermal resistance. Therefore, the temperature difference between the upper and lower plates is given by:

$$
\Delta T_{\text {plates }}=\delta T_{u}+\Delta T_{\text {sample }}+\delta T_{l}
$$

where $\delta T_{u}$ and $\delta T_{l}\left({ }^{\circ} \mathrm{C}\right)$ are the temperature differences between upper plate and sample surface, and between sample surface and lower plate, respectively. The contact thermal resistance $R\left(\mathrm{~m}^{2} \mathrm{~K}\right.$ $\left.\mathrm{W}^{-1}\right)$ is:

$$
R=\frac{\delta T}{q^{\prime \prime}}
$$

where $q^{\prime \prime}\left(\mathrm{W} \mathrm{m}^{-2}\right)$ is the heat flow recorded through each plate. $R$ depends on the type of material, the interface pressure applied and the roughness of the sample. The electric signal $Q(V)$ recorded by the heat flow transducers is proportional to the heat flow $q^{\prime \prime}$ through a calibration factor $S_{c a l}\left[\mathrm{~W} \mathrm{~m}^{-2} \mathrm{~V}^{-1}\right]$ that is determined using standard materials with known thermal conductivity. $\mathrm{Q}$, which is recorded during the experiment, is related to the thermal conductivity as:

$$
Q=\frac{q^{\prime \prime}}{S_{c a l}}=\frac{\Delta T_{\text {plates }}}{\left(\frac{\Delta x}{\lambda}+2 R\right) \cdot S_{c a l}}
$$

where $\Delta x$ is the thickness of the sample. The absolute accuracy of the device is $\pm 3 \%$ in the conductivity range of $0.1 \div 10 \mathrm{~W} \mathrm{~m}^{-1} \mathrm{~K}^{-1}$. Silicon or glycerine paste or rubber pads of known thermal resistance can be employed to smooth the problem of contact resistance. The measurements were carried out at $20^{\circ} \mathrm{C}$ with a $\Delta T=10^{\circ} \mathrm{C}$ between the upper $\left(25^{\circ} \mathrm{C}\right)$ and lower $\left(15^{\circ} \mathrm{C}\right)$ plate and the average of 10 sets of measurements was taken as final value.

\subsection{Sample preparation}

274 The whole sample collection was divided into two main datasets: dataset1 and dataset2. Dataset1 275 included all the 23 rock samples while dataset2 represents a subset of dataset1, namely nine representative samples. Regarding thermal conductivity (see Section 2.2), most of samples of 
dataset1 were analysed with two methods (OS and TLS), whereas dataset2 was additionally tested with other two techniques (TDB and GHP).

279 Thermal conductivity in all 23 samples was studied in the two main directions, i.e. parallel $\left(\lambda_{\text {par }}\right)$ and 280 perpendicular $\left(\lambda_{\text {per }}\right)$ to the main foliation. Five of the samples showed no clear foliation and $\mathrm{K}_{\mathrm{T}}<1.1$; these are classified as thermally homogeneous and an average effective value was reported. This procedure was adopted in both OS and TLS. For the measurements with OS, the samples were cut according to the foliation in order to obtain two perpendicular polished surfaces upon which the coating layer was applied. For the TLS analyses, previously cut and polished sample surfaces were drilled with a $4 \mathrm{~mm}$ rotary hammer bit to host the RK-1 single needle sensor. Two perpendicular drillings were performed in eleven out of twenty-three samples. Parallel and perpendicular conductivity values were calculated with the same methodology adopted for OS (Popov et al. 2016) and the anisotropy factor calculated.

Owing to issues related to obtain samples with the size and characteristics required by both TDB and GHP, cylindrical rock specimens were prepared from samples of dataset2 by means of a diamond-head corer and, through the use of a fine abrasive, both surfaces were rubbed down to get flat (within $0.1 \mathrm{~mm}$ ), parallel and smooth surfaces (within $0.03 \mathrm{~mm}$ ). Finally, the obtained core specimens had cylindrical shape, $25 \pm 0.1 \mathrm{~mm}$ in diameter and $20 \pm 0.5 \mathrm{~mm}$ in thickness. To improve the contact between rock specimen and the blocks (TDB) and plates (GHP), a film of silicone paste of about $0.1 \mathrm{~mm}$ was smeared on both samples surfaces.

Samples for OS and TLS are relatively easy to prepare, requiring a cut and painted surface (OS) or a drilled hole (TLS). In contrast TDB and GHP require core drilling followed by precision grinding, making their preparation critical to the success of the analysis.

\subsection{Compressional wave velocity and density}

301 The compressional wave velocity test is a non-destructive method based on the principle that pulse velocity of ultrasound waves, propagating through a solid material, depends on the density and the elastic properties of that material (AI-Khafaji and Purnell 2016). The commercial device PUNDIT Lab (by Proceq Switzerland) was used in this study. The apparatus is coupled with a pair of transducers that transmit and receive waves with a central frequency of $54 \mathrm{kHz}$, working on ASTM D2845 (2008) procedure. The tests were performed on the samples as analysed by the OS technique, as flat surfaces are necessary to make good contact between the specimen and the transducers. On each 
sample, 25-30 measurements were carried out to get accurate results and the average between these acquisitions was calculated.

Density was obtained by weighing the samples after water saturation under vacuum and measuring their volume through immersion in water. Samples were then oven-dried at $70{ }^{\circ} \mathrm{C}$ for one day in order to obtain the dry mass and to infer porosity. All the samples denoted negligible porosity (<3\%) and thus water content was assumed to be of negligible importance on the measurements of petrophysical properties.

\subsection{Mineralogical composition (XRD)}

The mineralogical composition of the samples of dataset 2 was investigated by means of powder X-Ray diffraction (XRD) on crystalline samples. The measurements were performed with the Philips X'Pert-Pro device (Malvern Panalytical (C2018) consisting of a Bragg-Brentano geometry and equipped with a stationary, centrally placed, X-ray tube. The tube was operated using a CuK $\alpha$ radiation at $40 \mathrm{~mA}, 40 \mathrm{kV}$ and $1.5417 \AA$. Spectra were recorded in the $2 \theta$ range $5-70^{\circ}$ with a $15 \mathrm{~s}$ counting time and $0.008^{\circ} 2 \theta$ step.

A qualitative analysis was firstly performed, distinguishing between two defined phase structures of calcite and quartz present in each sample. The peak shape was modelled with a Pseudo-Voigt function of which, the FWHM (Full Width of Half Maximum), was refined as a function of $2 \theta$ taking into account both Gaussian and Lorentzian broadening. The refinement was carried out in particular in the space group $R-3 c$ (calcite), $P 3_{2} 21$ (quartz).

In order to get an alternative estimate of the accuracy of the refined structural data, a comparison among the set of structural parameters obtained using different refinement strategies on the same diffraction data was carried out. These comparisons show that realistic estimates of the error bars are $\pm 0.001 \AA$ for the cell parameters. The error in the estimation of the phase content is $\pm 1 \% \mathrm{wt}$.

\section{RESULTS}

\subsection{Dataset1}

The bulk thermal conductivity values of dataset 1 were measured by means of OS in the University of Bergen's laboratory (Tab. 2) and with TLS in the University of Torino's laboratory (Tab. 3). The samples coded B (e.g. 1_B) indicate that the specific rock specimens were measured in Bergen only; those coded T (e.g. 1_T) indicate that they were analysed in Torino only; when the specimen is called 
BT (e.g. 4_BT) means that the same rock specimen was measured by both techniques. This should warn the reader that differences between 1_B and 1_T can even be related to the sample heterogeneity and not only to the adopted techniques. Some samples (3_T, 9_BT, 13_BT, 17_BT, 18_BT, 19_BT) broke during preparation and it was not possible to analyse neither thermal conductivity with TLS or OS, nor sonic velocity.

344 The standard deviations reported for OS are related to the values measured along the scanning lines and thus due to the intrinsic heterogeneity of the rock samples. These cannot be compared to the standard deviations of the TLS, which relate to the repeatability and precision of the KD2 Pro. The standard deviations of the effective thermal conductivity (three runs along each scanning line) measured with the OS were $\pm 0.7 \%$ on average, with a maximum of $\pm 1.6 \%$ and a minimum of \pm $0.1 \%$. OS and TLS bulk thermal conductivity was calculated as a geometric average between parallel and perpendicular values. $K_{T}$ refers to the anisotropy factor given by the parallel to perpendicular 351 values ratio.

352 Mica-schists and amphibolites of the Nordåsvatn Complex show significant thermal anisotropy, with 353 parallel values higher than perpendicular ones by $50 \%$ in OS and $46 \%$ in TLS data. The marbles of the Storeveit Group present an isotropic nature as expected, with anisotropy factor always smaller than 1.1. The Gamlehaugen Complex shows clear thermal anisotropy in the quartz-schists and quartz-mica-schists $\left(K_{T}>1.2\right)$, in contrast to the general isotropic texture of both augen and mylonitic gneisses $\left(K_{T}<1.1\right)$. In absolute terms, the whole dataset is rather homogeneous, a bit surprising given the presence of high quartz-content lithotypes. Low values of quartz-schists 21,22 and 23 can be explained by abundant presence of muscovite, which presents strong anisotropy in thermal conductivity $\left(0.6 \mathrm{~W} \mathrm{~m}^{-1} \mathrm{~K}^{-1}\right.$ perpendicular, $3.9 \mathrm{~W} \mathrm{~m}^{-1} \mathrm{~K}^{-1}$ parallel; Clauser and Huenges 1995). The OS average thermal conductivity is $2.75 \mathrm{~W} \mathrm{~m}^{-1} \mathrm{~K}^{-1}$ with a standard deviation of 0.29; TLS data records an average conductivity of $2.18 \mathrm{~W} \mathrm{~m}^{-1} \mathrm{~K}^{-1}$ with a minimum of 1.37 and maximum of 3.16 (standard deviation 0.51).

Table 2 Thermal conductivity $\lambda\left(\mathrm{W} \mathrm{m}^{-1} \mathrm{~K}^{-1}\right)$ and anisotropy factor $K_{T}$ of dataset 1 measured by means of $O S$.

\begin{tabular}{l|c|cccccc|c} 
Sample ID & Lithology & $\boldsymbol{\lambda}_{\text {bulk }}$ & $\boldsymbol{\lambda}_{\text {perp }}$ & St. dev. & $\boldsymbol{\lambda}_{\text {par }}$ & $\boldsymbol{S}$ St. dev. & $\boldsymbol{K}_{\boldsymbol{T}}$ & Comments \\
\hline 1_B & QMS & 3.088 & 2.159 & 0.675 & 4.416 & 1.168 & 2.05 & \\
2_B & AM & 2.681 & 2.322 & 0.484 & 3.095 & 0.273 & 1.33 & \\
3_B & AM & 2.606 & 2.137 & 0.724 & 3.178 & 0.239 & 1.49 & \\
4_BT & AM & 3.128 & 2.652 & 0.508 & 3.689 & 0.351 & 1.39 & \\
5_BT & AMS & 2.682 & 2.373 & 0.436 & 3.031 & 0.239 & 1.28 & \\
6_BT & AM & 2.643 & 2.165 & 0.415 & 3.226 & 0.335 & 1.49 &
\end{tabular}




\begin{tabular}{l|l|cccccc|c} 
7_BT & MB & 2.934 & $/$ & $/$ & 2.934 & 0.174 & $/$ & isotropic \\
8_BT & MB & 2.854 & $/$ & $/$ & 2.854 & 0.128 & $/$ & isotropic \\
9_BT & MB & 2.778 & 2.671 & 0.415 & 2.889 & 0.125 & 1.08 & \\
10_BT & MB & 2.995 & 2.913 & 0.621 & 3.079 & 0.194 & 1.06 & \\
11_BT & MC & 2.328 & 1.888 & 0.867 & 2.870 & 0.552 & 1.52 & \\
12_BT & MS & 2.826 & 2.461 & 0.470 & 3.246 & 0.199 & 1.32 & \\
13_BT & MS & 2.332 & 1.620 & 0.976 & 3.356 & 1.447 & 2.07 & \\
14_B & MS & 2.423 & 2.228 & 0.391 & 2.636 & 0.290 & 1.18 & \\
15_B & QMS & 3.333 & 3.233 & 0.540 & 3.437 & 0.169 & 1.06 & isotropic \\
16_B & AG & 2.955 & $/$ & $/$ & 2.955 & 0.189 & $/$ & \\
17_BT & MS & 2.275 & 2.069 & 0.269 & 2.500 & 0.379 & 1.21 & isotropic \\
18_BT & MS & 2.906 & $/$ & $/$ & 2.906 & 0.862 & $/$ & \\
20_B & AG & 2.946 & 2.924 & 0.645 & 2.969 & 0.299 & 1.02 & \\
21_B & QS & 2.677 & 2.286 & 1.288 & 3.134 & 0.563 & 1.37 & \\
22_BT & QS & 2.842 & 2.300 & 0.884 & 3.511 & 0.308 & 1.53 & \\
23_B & QS & 2.301 & 2.103 & 0.425 & 2.518 & 0.280 & 1.20 & \\
\hline
\end{tabular}

366

Table 3 Thermal conductivity $\lambda\left(\mathrm{W} \mathrm{m}^{-1} \mathrm{~K}^{-1}\right)$ values and anisotropy factor $K_{T}$ obtained with TLS.

\begin{tabular}{l|c|cccccc|c} 
Sample ID & Lithology & $\lambda_{\text {bulk }}$ & $\lambda_{\text {perp }}$ & St. dev. & $\lambda_{\text {par }}$ & St. dev. & $\boldsymbol{K}_{T}$ & Comments \\
\hline 1_T & QMS & 1.367 & 1.006 & 0.060 & 1.859 & 0.074 & 1.85 & \\
2_T & AM & 2.422 & 2.745 & 0.072 & 2.137 & 0.104 & 0.78 & \\
4_BT * & AM & 2.743 & $/$ & $/$ & 2.743 & 0.097 & $/$ & only perp. drilling possible \\
5_BT * & AMS & 2.266 & $/$ & $/$ & 2.266 & 0.045 & $/$ & only perp. drilling possible \\
6_BT & AM & 1.911 & 1.613 & 0.035 & 2.263 & 0.107 & 1.40 & isotropic \\
7_BT & MB & 2.518 & $/$ & $/$ & 2.518 & 0.127 & $/$ & isotropic \\
8_BT & MB & 2.448 & $/$ & $/$ & 2.448 & 0.175 & $/$ & only par. drilling possible \\
10_BT ** & MB & 2.317 & 2.317 & 0.137 & $/$ & $/$ & $/$ & \\
11_BT & MC & 1.797 & 1.291 & 0.096 & 2.501 & 0.165 & 1.94 & isotropic \\
12_BT & MS & 2.042 & 1.538 & 0.130 & 2.712 & 0.055 & 1.76 & \\
14_T & MS & 1.773 & 1.454 & 0.084 & 2.162 & 0.067 & 1.49 & \\
15_T & QMS & 3.023 & 2.513 & 0.184 & 3.636 & 0.095 & 1.45 & on \\
16_T & AG & 3.155 & $/$ & $/$ & 3.156 & 0.456 & $/$ & \\
20_T & AG & 2.066 & 1.856 & 0.073 & 2.299 & 0.146 & 1.24 & only perp. drilling possible \\
21_T* & QS & 1.426 & $/$ & $/$ & 1.426 & 0.034 & $/$ & \\
22_BT & QS & 2.175 & 1.779 & 0.088 & 2.659 & 0.152 & 1.50 & \\
23_T & QS & 1.621 & 1.699 & 0.038 & 1.547 & 0.042 & 0.91 & \\
\hline
\end{tabular}

* parallel value; ${ }^{* *}$ perpendicular value

370 Comparing the results of the different techniques, we observe a general underestimation of TLS 371 with respect to OS, both for the bulk conductivity and $\lambda_{\text {par }}$ and $\lambda_{\text {per }}$ (Fig. 2). TLS underestimates 372 thermal conductivity with respect to OS, with a maximum difference of $56 \%$ (sample 1 ) in the bulk value. Generally, the higher biases occur in the parallel analyses (58\%) than in those perpendicular 
(54\%). By taking OS as a reference, $68 \%$ of the TLS results underestimate the thermal conductivity of the rock samples analysed by a minimum of $10 \%$ to a maximum of $30 \%$; for the $24 \%$, the underestimate is more than $30 \%$ and only few outliers (8\%) overestimate it. A significant difference among bulk, parallel and perpendicular values is not clearly evident in Figure 2 . If only the BT samples are taken into consideration, the underestimate of TLS with respect to OS is on average $20.1 \%, 20.3 \%$ and $27.5 \%$ for bulk, parallel and perpendicular values respectively, with a minimum 381 of $12.3 \%$ (4_BT bulk) and maximum of $37.5 \%$ (12_BT perpendicular).

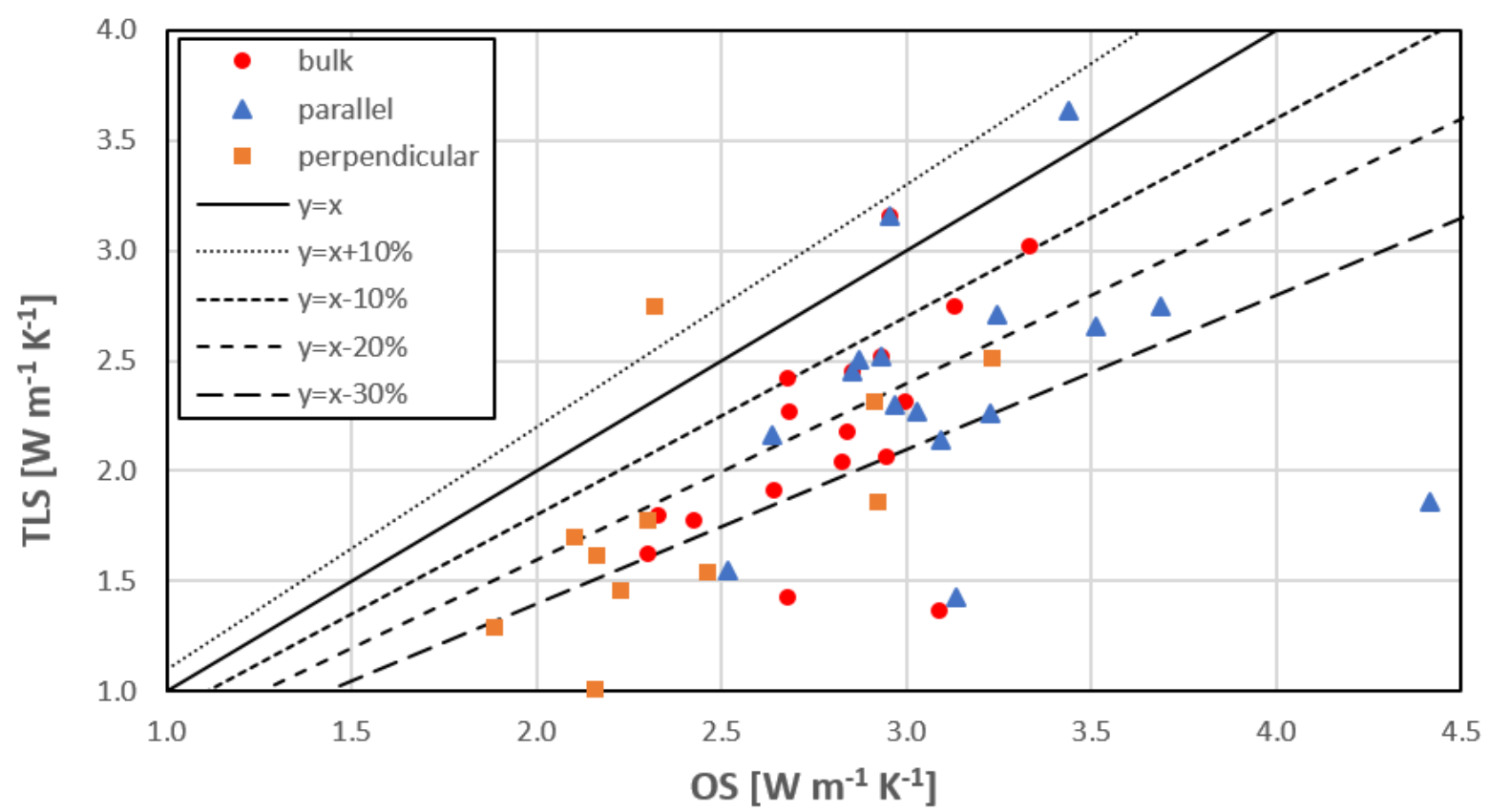

382 383 384 385 386 387 388 389 390

Figure 2 Comparison between OS and TLS bulk, parallel and perpendicular values of thermal conductivity

No clear direct correlation between bulk thermal conductivity (from OS technique) and P-wave velocity is observed in dataset1 (Fig. 3). Mielke et al. (2017) also showed that low-porosity rocks, as those investigated in this paper, present weak correlations. It is nevertheless interesting to note the contrast between properties when considered parallel and perpendicular to the main rock foliation. Perpendicular conductivity values grow with increasing perpendicular sonic velocity, while parallel values exhibit an inverse trend. Therefore, it is shown that only along the direction perpendicular to foliation heat and P-waves propagation in the medium follow similar patterns. Conversely, when analysing the sample along the main foliation, propagation paths might not be necessarily the same. Unfortunately, due to the heterogeneity of the collection and the limited number of samples, this cannot be related to specific rock features. It would be necessary to investigate further, but this goes beyond the purpose of the present paper. When comparing the anisotropy factors (Tab. 4), 
396 the data are quite similar, with eight out of twelve samples showing a $\mathrm{K}_{\mathrm{S}} / \mathrm{K}_{\mathrm{T}}$ ratio within the $0.85 \div$ 3971.15 range (i.e. 15\% bias) and the best results occurring in the BT samples (same specimen analysed 398 by both techniques).

399

400

401 402 403 404

405

406

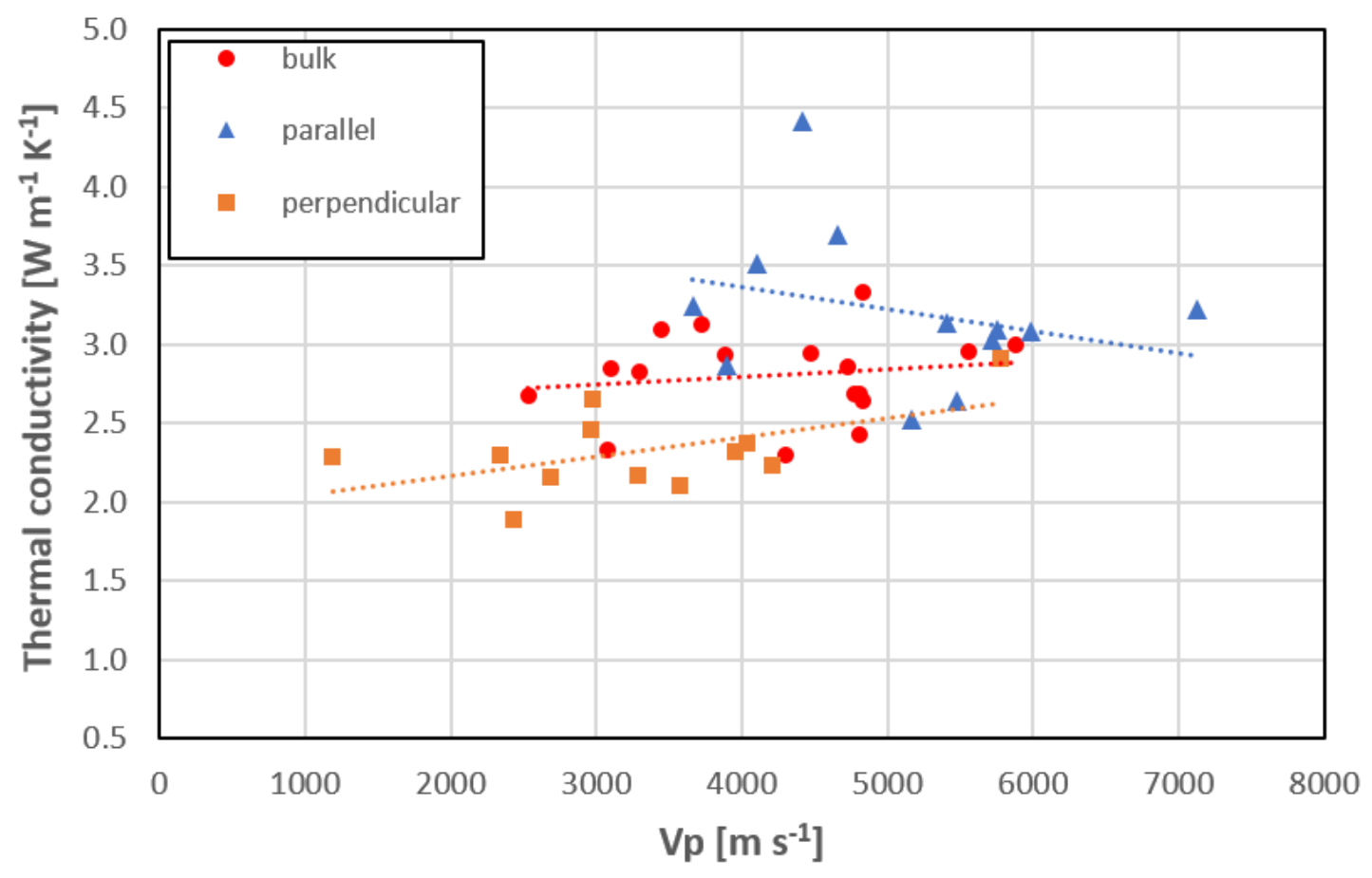

Figure 3 Relationship between thermal conductivity (OS technique) and P-wave velocity.

Table 4 P-wave velocity $V p\left(\mathrm{~m} \mathrm{~s}^{-1}\right)$, sonic $\left(K_{S}\right)$ and thermal anisotropy ( $K_{T}$ from OS) of dataset1. $N$ is the number of measurements.

\begin{tabular}{c|c|c|ccc|ccc|ccc} 
Sample ID & Lithology & $\boldsymbol{V p}_{\text {bulk }}$ & $\boldsymbol{V} \boldsymbol{p}_{\text {perp }}$ & $\begin{array}{c}\text { St. } \\
\text { dev. }\end{array}$ & $\boldsymbol{N}$ & $\boldsymbol{V p}$ par & $\begin{array}{c}\text { St. } \\
\text { dev. }\end{array}$ & $\boldsymbol{N}$ & $\boldsymbol{K}_{S}$ & $\boldsymbol{K}_{T}$ & $\boldsymbol{K}_{S} / \boldsymbol{K}_{T}$ \\
\hline 1_T/1_B & MS & 3448 & 2691 & 45 & 27 & 4418 & 353 & 28 & 1.64 & 2.05 & 0.80 \\
2_T/2_B & AM & 4769 & 3953 & 154 & 27 & 5753 & 165 & 27 & 1.46 & 1.33 & 1.09 \\
4_BT & AM & 3727 & 2978 & 114 & 27 & 4664 & 136 & 27 & 1.57 & 1.39 & 1.13 \\
5_BT & AMS & 4805 & 4038 & 124 & 28 & 5719 & 171 & 27 & 1.42 & 1.28 & 1.11 \\
6_BT & AM & 4836 & 3284 & 92 & 28 & 7123 & 296 & 27 & 2.17 & 1.49 & 1.46 \\
10_BT & MB & 5877 & 5774 & 274 & 26 & 5982 & 107 & 27 & 1.04 & 1.06 & 0.98 \\
11_BT & MC & 3082 & 2435 & 27 & 26 & 3901 & 118 & 26 & 1.60 & 1.52 & 1.05 \\
12_BT & MS & 3295 & 2963 & 73 & 26 & 3664 & 58 & 26 & 1.24 & 1.32 & 0.94 \\
14_T/14 B & MS & 4804 & 4209 & 127 & 26 & 5483 & 226 & 27 & 1.30 & 1.18 & 1.10 \\
21_T/21_B & QS & 2533 & 1187 & 57 & 27 & 5407 & 209 & 27 & 4.55 & 1.37 & 3.32 \\
22_BT & QS & 3099 & 2343 & 37 & 27 & 4100 & 123 & 27 & 1.75 & 1.53 & 1.15 \\
23_T/23_B & QS & 4301 & 3577 & 128 & 27 & 5172 & 81 & 27 & 1.45 & 1.20 & 1.21 \\
\hline
\end{tabular}

\subsection{Dataset2}


Dataset2 comprised nine of the dataset1 samples further studied using GHP and TLS. Of the nine specimens, 3 are perpendicular and one is parallel to the main foliation; the rest are from isotropic samples. Cylindrical shape specimens were obtained from the samples analysed with the OS and TLS techniques (samples BT) or by the TLS only (samples T).

Table 5 Comparison of thermal conductivity results of dataset2 measured with the four techniques (see text); the accuracy of each technique is in brackets. Last column reports average values from literature

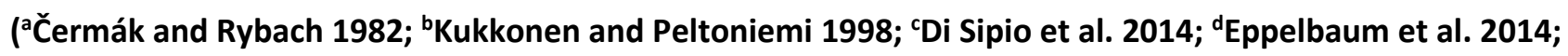

eRamstadt et al. 2015; ${ }^{\text {}}$ Mielke et al. 2017).

\begin{tabular}{|c|c|c|c|c|c|c|c|}
\hline Sample ID & Lithology & Orientation & $\begin{array}{c}T D B \\
( \pm 5 \%)\end{array}$ & $\begin{array}{c}\text { OS } \\
( \pm 5 \%)\end{array}$ & $\begin{array}{c}G H P \\
( \pm 3 \%)\end{array}$ & $\begin{array}{c}T L S \\
( \pm 10 \%)\end{array}$ & Literature \\
\hline 1_T & QMS & Parallel & 4.23 & $4.42 *$ & 3.98 & 1.86 & $3.8^{d}$ \\
\hline 7_BT & $\mathrm{MB}$ & Isotropic & 2.56 & 2.93 & 2.76 & 2.52 & $2.7 \div 2.8^{a, f}$ \\
\hline 10_BT & $\mathrm{MB}$ & Isotropic & 2.90 & 3.00 & 2.62 & $2.32 * *$ & $2.7 \div 2.8^{a, f}$ \\
\hline 11_BT & $\mathrm{MC}$ & Isotropic & 2.29 & 2.33 & 2.91 & 1.80 & $2.6^{\mathrm{e}}$ \\
\hline 12_BT & MS & Perpendicular & 2.89 & 2.46 & 2.32 & 1.54 & $2.5 \div 2.8^{d, e}$ \\
\hline 14_T & MS & Parallel & 2.44 & $2.64^{*}$ & 2.38 & 2.16 & $2.5 \div 2.8^{d, e}$ \\
\hline 15_T & QMS & Parallel & 3.36 & $3.44^{*}$ & 3.96 & 3.64 & $3.8^{d}$ \\
\hline 16_T & AG & Isotropic & 2.91 & $2.96 *$ & 2.88 & 3.16 & $2.4 \div 3.0^{a, b, c, e}$ \\
\hline 20_T & $A G$ & Isotropic & 2.83 & $2.95^{*}$ & 2.90 & 2.07 & $2.4 \div 3.0^{a, b, c, e}$ \\
\hline
\end{tabular}

The results are consistent with average values in literature (Tab. 5). The analysis of dataset2 confirms that TLS underestimates thermal conductivity with respect to TDB (-26\% on average) and GHP (-24\% on average), with a maximum of more than $50 \%$ in sample 1_T, which is highly anisotropic. It is worth stressing that in four samples (7_BT, 14_T, 15_T and 16_T) the bias with GHP is within the $10 \%$ accuracy expected for the TLS device. In particular, in the very homogeneous and isotropic augen gneiss 16 _T, TLS registers a thermal conductivity higher than TDB, OS and GHP by $9 \%, 7 \%$ and $10 \%$ respectively. A conductivity greater than TDB (8\%) and OS (6\%) is also given by TLS in the same lithology of 15_T (Fig. 4).

426 On the contrary, a good general agreement between OS, TDB and GHP is observed (Fig. 5): a 7-8\% divergence from the overall mean is registered compared to an $18 \%$ average bias recorded by TLS. In the five samples in which the TLS bias is greater than the accuracy of the devices used for the analyses (error bars do not overlap), that value was discarded and a new average calculated (Tab. 6). The new values were then adopted to compare the different techniques. TDB and OS show an average divergence of $6 \%$ with maximum of $16.8 \%$ and $13.7 \%$ in 12_BT and 7_BT respectively. 
Moreover, TDB and OS are within $5 \%$ in six out of nine samples. Comparisons between GHP and OS, 433 and GHP and TDB have worse accordance, with average 9.8\% and 10.4\% respectively, and only in 434 two and three cases better than 5\%. The greatest biases are observed in BT samples, wherein the 435 same specimen was analysed by means of the three techniques: in particular, the largest deviations 436 (24.7\% and 22.3\%) were obtained between TDB and GHP, which used the same core sample. The 437 discrepancy could be attributed to the difference between static and transient analyses: in three 438 out of nine samples (11_BT, 12_BT and 15_T), TDB and GHP error bars do not overlap. 439

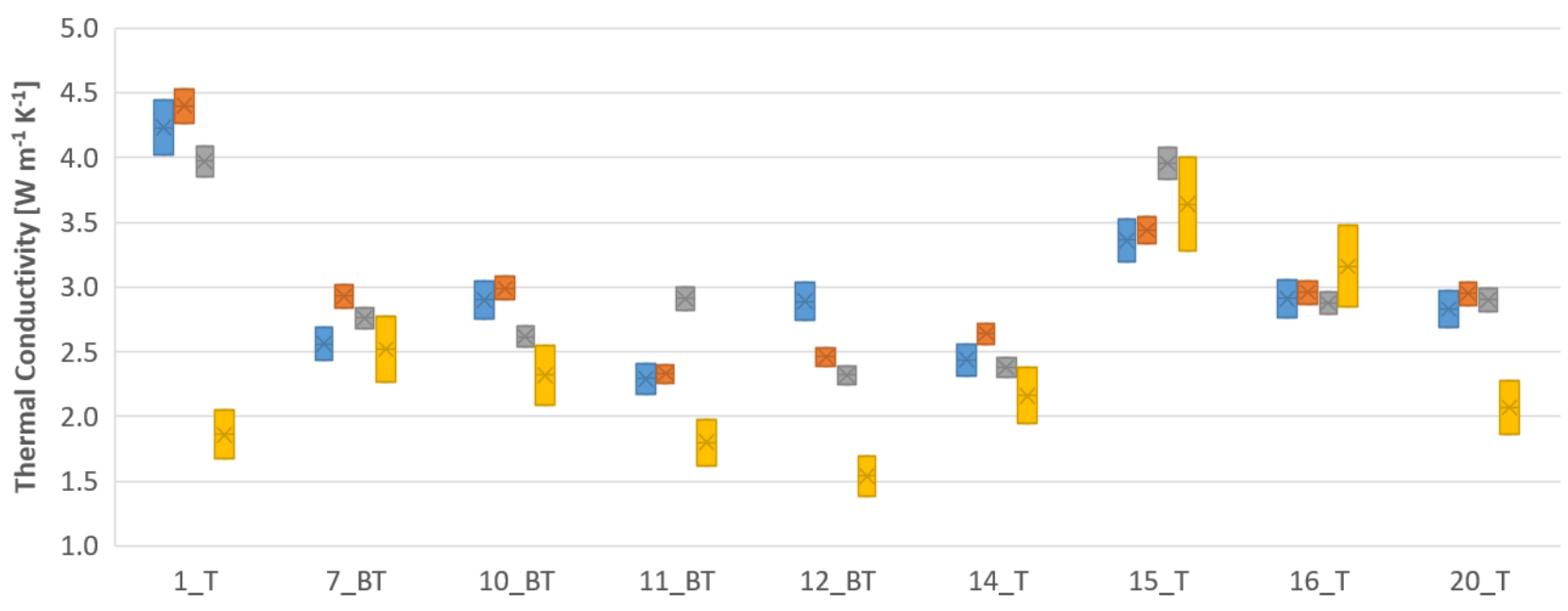

Figure 4 Thermal conductivity results of dataset2.

Table 6 Comparison of thermal conductivity results for dataset2.

\begin{tabular}{|c|c|c|c|c|c|c|c|c|c|c|}
\hline \multirow[b]{2}{*}{$\begin{array}{c}\text { Sample } \\
\text { ID }\end{array}$} & \multirow[b]{2}{*}{ Lithology } & \multirow{2}{*}{$\begin{array}{c}\text { Mean all } \\
\text { methods } \\
\left(W m^{-1} K^{-1}\right)\end{array}$} & \multicolumn{4}{|c|}{ Differences to mean } & \multirow{2}{*}{$\begin{array}{c}\text { Recalculated } \\
\text { mean } w / o T L S \\
\left(W m^{-1} K^{-1}\right)\end{array}$} & \multicolumn{3}{|c|}{ Differences between pairs } \\
\hline & & & $\begin{array}{l}\text { TDB } \\
{[\%]}\end{array}$ & $\begin{array}{c}\text { OS } \\
\text { [\%] }\end{array}$ & $\begin{array}{c}\text { GHP } \\
{[\%]}\end{array}$ & $\begin{array}{l}\text { TLS } \\
\text { [\%] }\end{array}$ & & $\begin{array}{c}T D B-G H P \\
{[\%]}\end{array}$ & $\begin{array}{c}\text { TDB-OS } \\
\text { [\%] }\end{array}$ & $\begin{array}{c}\text { OS-GHP } \\
{[\%]}\end{array}$ \\
\hline 1_T & QMS & 3.62 & 17.0 & 21.7 & 9.8 & -48.6 & 4.20 & 6.2 & 4.2 & 10.2 \\
\hline 7_BT & $M B$ & 2.69 & -4.9 & 8.8 & 2.5 & -6.4 & $2.69 *$ & 7.4 & 13.7 & 6.3 \\
\hline 10_BT & MB & 2.71 & 7.1 & 10.5 & -3.3 & -14.3 & 2.84 & 9.9 & 3.2 & 13.1 \\
\hline 11_BT & MC & 2.33 & -1.8 & -0.1 & 24.8 & -22.8 & 2.51 & 24.7 & 1.6 & 23.1 \\
\hline 12_BT & MS & 2.30 & 25.5 & 6.8 & 0.8 & -33.1 & 2.56 & 22.3 & 16.8 & 5.5 \\
\hline 14_T & MS & 2.41 & 1.5 & 9.8 & -1.0 & -10.2 & $2.41^{*}$ & 2.5 & 8.3 & 10.8 \\
\hline 15_T & QMS & 3.60 & -6.6 & -4.4 & 9.9 & 1.2 & $3.60 *$ & 16.5 & 2.2 & 14.3 \\
\hline 16_T & $A G$ & 2.98 & -2.2 & -0.6 & -3.4 & 6.2 & $2.98^{*}$ & 1.1 & 1.7 & 2.8 \\
\hline 20_T & $A G$ & 2.69 & 5.3 & 9.8 & 7.9 & -23.0 & 2.89 & 2.4 & 4.2 & 1.7 \\
\hline \multicolumn{3}{|c|}{ Mean Diff. (Abs.) } & $8.0 \%$ & $8.1 \%$ & $7.0 \%$ & $18.4 \%$ & & $10.4 \%$ & $6.2 \%$ & $9.8 \%$ \\
\hline
\end{tabular}


* value of the first column

447

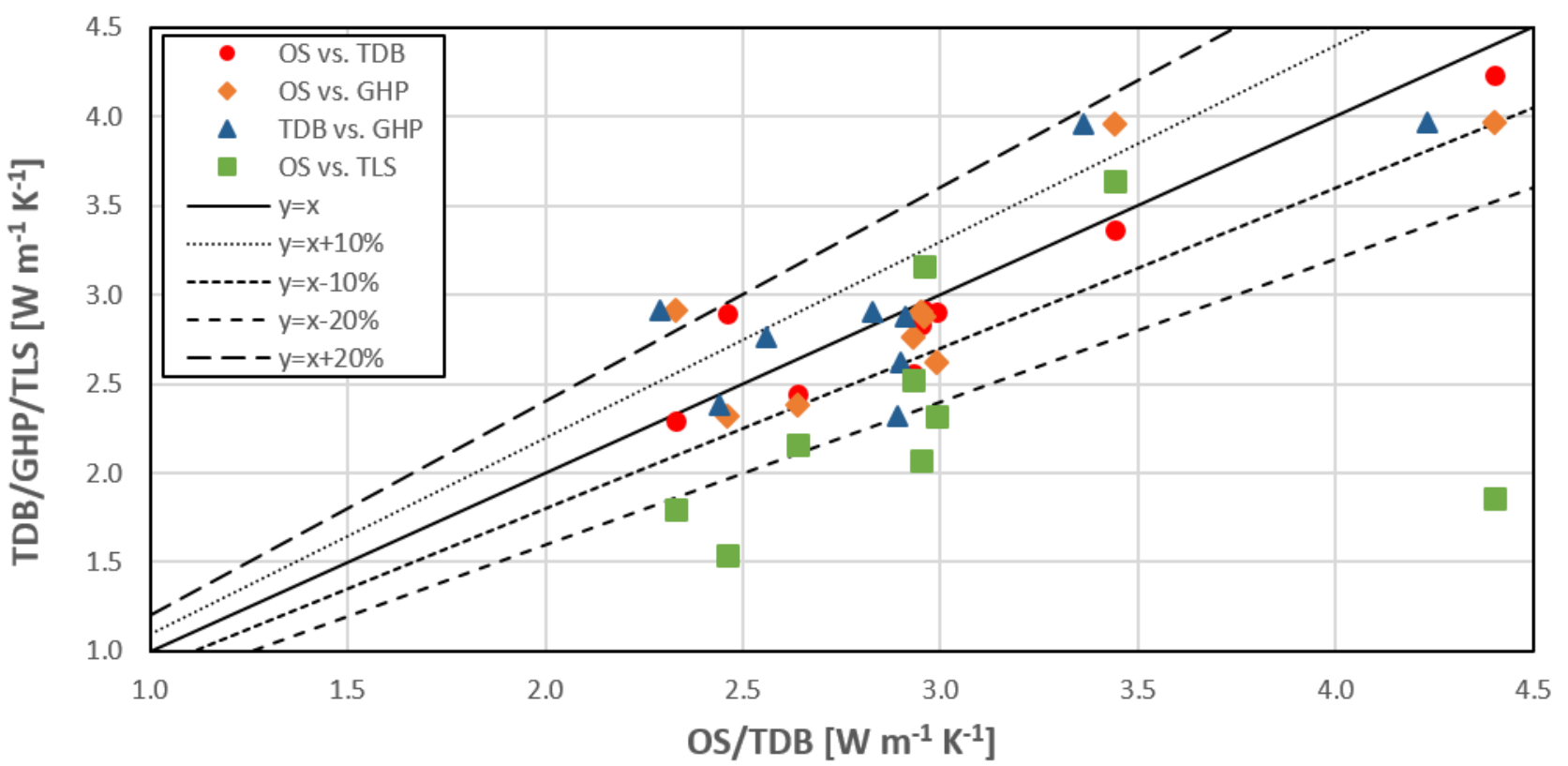

Figure 5 Comparison of conductivity measurement techniques for dataset2.

450

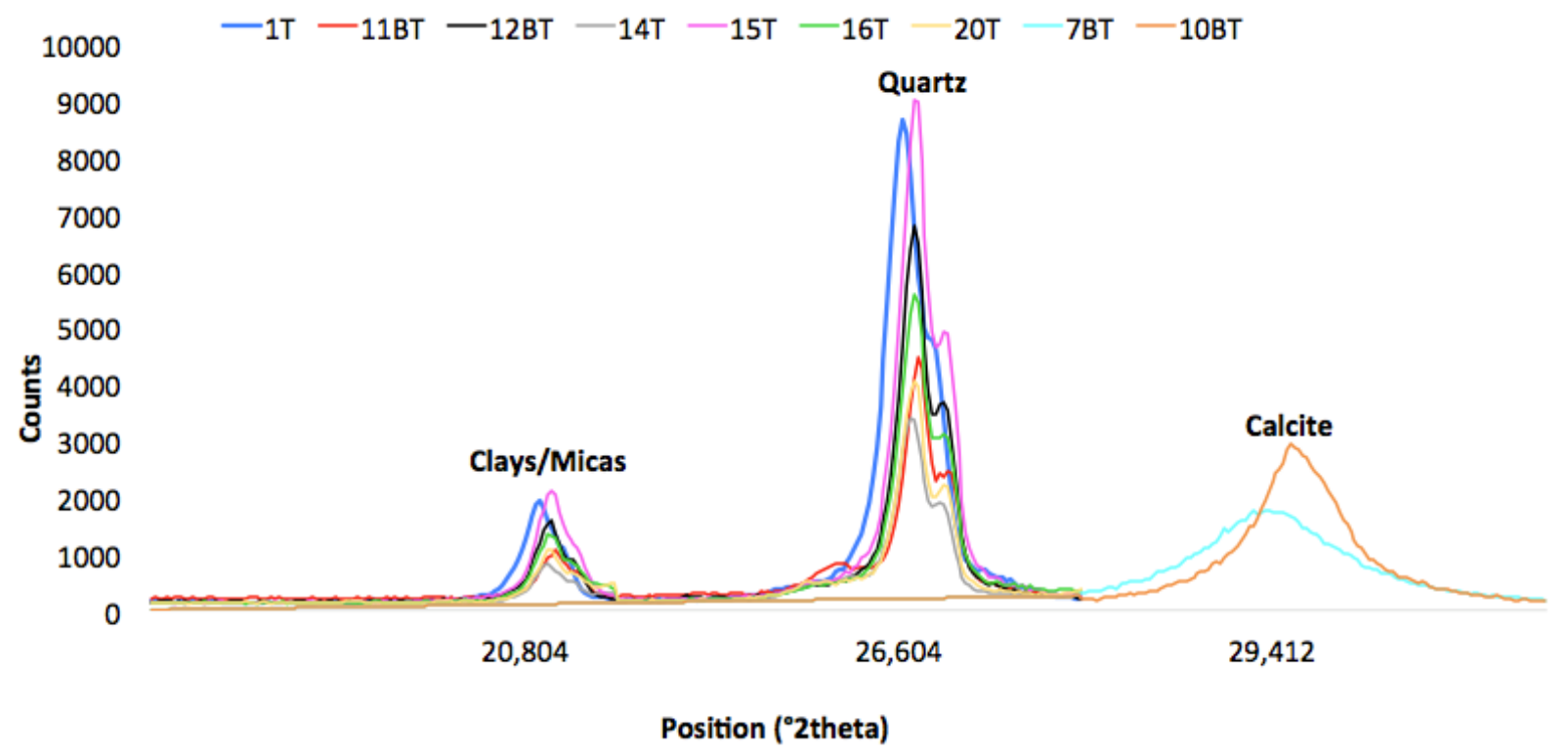

Figure 6 XRD results of the main mineral groups of dataset2 samples.

454 XRD analyses show the bulk mineralogy of the samples, entirely quartz and clay/mica except two 455 with carbonate (Fig. 6). These analyses were performed because many of the samples have a 456 microcrystalline structure, so the recognition of the mineral phases with optical techniques is often 457 difficult and in many cases not useful from a quantitative point of view. Quartz and micas are the 458 main mineral phases of the mica-schists and gneisses, while calcite is predominant in the marbles 
459 (samples 10_BT and 7_BT; Fig. 6). As expected, Table 6 shows that higher quartz content 460 corresponds to higher thermal conductivity. For example, the quartz-mica schist samples 1_T and 461 15_T have mean conductivities of 4.2 and $3.6 \mathrm{~W} \mathrm{~m}^{-1} \mathrm{~K}^{-1}$ respectively. These samples also have low 462 density, consistent with the low relative density of quartz and mica (Fig. 7). The high content of 463 micas (likely muscovite and biotite) might mask significant differences between silicate and 464 carbonate samples, given that calcite thermal conductivity $\left(3.2 \div 3.6 \mathrm{~W} \mathrm{~m}^{-1} \mathrm{~K}^{-1}\right.$; Clauser and Huenges

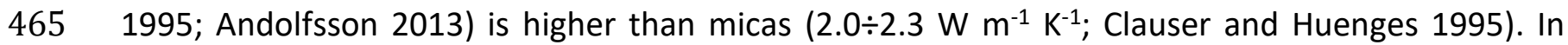
466 samples with calcite or likely other dense mineral phases (e.g. olivine), not clearly detected in the 467 XRD study, we noticed lower thermal conductivity which is accompanied by higher density values 468 (e.g. 10_BT and 11_BT, Fig. 7). The thermal conductivity and density of 10_BT is consistent with 469 isotropic marble. 11_BT is characterized by the highest density and lowest conductivity. Its density 470 and thermal conductivity are consistent with the facies description of clasts of trondjemite, 471 epidosite and amphibolite (Fossen 1989). Density ranges for these rocks are: trondjemite 2.7, 472 epidosite $2.8 \div 3.0$ and amphibolite $2.9 \div 3.1 \mathrm{~g} \mathrm{~cm}^{-3}$; thermal conductivity: trondjemite $1.8 \div 2.6$, 473 epidosite $2.4 \div 4.5$ and amphibolite $2.2 \div 2.9 \mathrm{~W} \mathrm{~m}^{-1} \mathrm{~K}^{-1}$ (Popov et al. 1999; Miao et al. 2014, Merriman 474 et al. 2013). The XRD shows relatively low peaks for quartz and mica, and, at slightly lower 2-theta 475 than quartz, some additional low peaks not present in the other samples (Fig. 6).

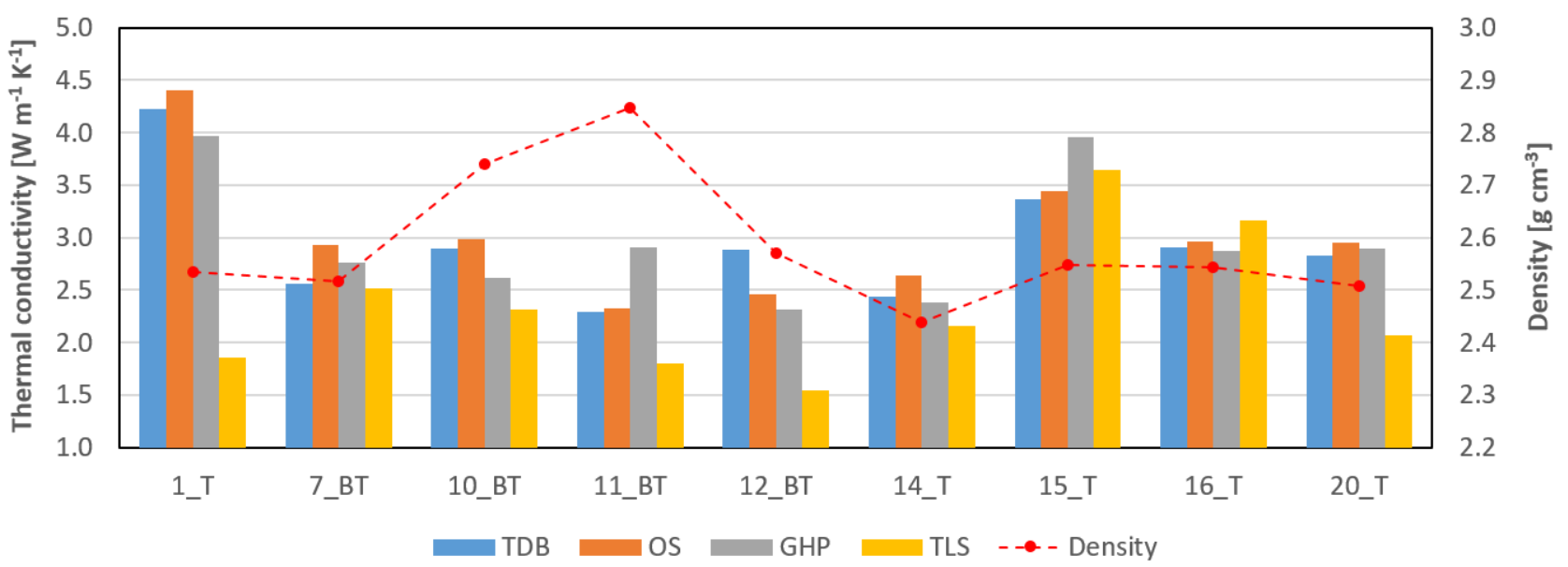

Figure 7 Comparison between thermal conductivity and density in dataset2.

\section{DISCUSSION}

480 Among the techniques used for the thermal conductivity analyses of our samples, it is reported in 481 the literature that TLS is a valid method to measure highly porous, soft materials (e.g. Di Sipio et al. 482 2014), but with hard materials the results may often be affected by large biases. In our analyses, 483 particular care has been adopted in sample preparation. Each sample was previously prepared with 
two parallel surfaces in order to have a $90^{\circ} \pm 5^{\circ}$ angle with the drill bit; a drill press was used to drill the sample to assure a precise perpendicular drilling; water was constantly poured in to safeguard the widia-diamond bit and facilitate the exit of drill cutting; the hole was cleaned up by removing dust and cuttings with compressed air after the end of drilling; the probe and the inner hole were carefully coated with thermal grease; finally, the probe was inserted slowly to allow trapped air to escape.

Despite the careful sample preparation, the TLS systematically showed low values with respect to the other three techniques. TLS gave lower conductivity than OS (more than $90 \%$ of samples in dataset1) and GHP and TDB (more than 65\% in dataset2). Anisotropy seems to have some influence, the average bias being $14 \%$ in isotropic against $27 \%$ in anisotropic rocks, even if isotropic samples 10_BT and 20_T showed biases of 23 and 30\%. By increasing the TLS values by $20 \%$, more than half of the samples would be within $10 \%$ of the OS value (dataset1). However, in dataset2 this would cause severe overestimation for samples 7_BT, 15_T and 16_T. In summary, we infer the "high" values are correct, and attribute the "low" values to problems with deficiencies in the sample preparation for TLS measurements. Clearly, TLS strongly depends on sample preparation and heterogeneity and anisotropy of the rock. Isotropic, homogeneous and competent (weathered samples could break during preparation) lithotypes can limit the bias to $<10 \%$ if care is taken in the measurement procedure above explained. For anisotropic and highly heterogeneous rocks, and weak or weathered samples, the other methods are preferable to avoid significant underestimation of the actual thermal conductivity.

Even though the GHP and the TDB methods are similar in sample preparation and precautions to limit the contact resistance were adopted (in two cases, 11_BT and 12_BT, the specimens were even the same), the results were similar in samples 7_BT, 16_T and 20_T, but significantly different in samples 10_BT, 11_BT, 12_BT and 15_T. A systematic explanation for the variation in results is not evident. Only minor influence on the results was found for the heterogeneity and anisotropy of the samples. It is nevertheless evident that the core preparation is crucial to get reliable results; but it also seems that other factors are important, such as the quality of the measuring stack (contact between plates/blocks and sample, accuracy of temperature sensors/heat flow meters) and the employment of standards (TDB) rather than previously obtained calibration curves (GHP). Smaller biases were obtained between GHP and OS, and TDB and OS, with the TDB-OS differences being consistently smaller than the others. Differences with OS are also related to the different measuring procedures. The OS scans the entire sample while the other techniques give instead more 
516 localized information. Thus, the OS can thoroughly characterize a rock sample with information

517 about heterogeneity and thermal anisotropy in an easier way in comparison to the other three

518 techniques. Another advantage of the OS is the simple sample preparation. Last but not least, the

519 problem of thermal contact resistance is bypassed. On the other hand, samples for OS analysis must 520 be big enough to neglect boundary effects (Popov et al. 2016), even if the energy input (heat and 521 speed) can be varied accordingly.

522 Finally, it is important to stress that OS is the fastest way to analyse thermal conductivity, not only 523 in terms of single measurement (1-2 min against 5-8 min with TDB and 60-70 min with GHP), but 524 also for the simplest sample preparation. The OS seems to be the best with friable and weathered 525 samples since there is no contact and only a flat surface is required, but micro-cracks are still a 526 problem. Nevertheless, if the sample is competent enough, drilling several cores with different 527 orientations allows evaluating thermal anisotropy also with GHP or TDB.

528 Bulk thermal conductivity and sonic velocity values did not show a clear direct correlation in the 529 collections under study, herein attributed to the low porosity of the samples (Mielke et al. 2017).

530 This could be related to the opposite trends observed in the parallel and perpendicular analyses, 531 that show an inverse and a direct relationship respectively. In the authors' knowledge, this has not 532 been reported in literature so far and deserves to be investigated further.

533 A clearly defined correlation between thermal conductivity and density was not recorded. However, 534 in quartz-rich samples we observed high thermal conductivity and low density as also observed by 535 Pasquale et al. (2015). On the contrary, in calcite-rich samples we noticed lower thermal 536 conductivity not related to a well-defined density value. The presence of micas is likely to mask major differences between silicate and carbonate samples.

\section{CONCLUSIONS}

540 A comparison among four different laboratory methodologies to analyse the rock thermal 541 conductivity was carried out. Steady state (GHP) and transient (TLS, TDB, OS) methods were adopted 542 and results compared to highlight qualities and flaws of the different techniques. Moreover, 543 compressional wave velocities, density and mineral composition were investigated. The results of 544 this study are preparatory for future activities that will encompass the set-up of numerical modelling 545 of the underground thermal structure of the BHE field in Bergen.

546 Among the four methods for measuring thermal conductivity, even if steady state techniques are 547 expected to be more accurate, our results indicate that TDB and OS give more congruent results. 
TLS, instead, systematically underestimates thermal conductivity in the investigated samples, confirming that it is hardly applicable to hard rocks. Due to heterogeneity, anisotropy and mechanical properties of the rocks, the use of at least two different techniques seems recommendable in investigations on rock thermal properties. An uncertainty of 5 to $10 \%$ is the best that one can expect even in good-quality and homogeneous samples. Geothermal modelling often relies on values of thermal conductivity without well-defined uncertainty boundaries. The inclusion of this uncertainty may increase the reliability of estimations.

\section{Acknowledgments}

557 The authors would like to thank the laboratory of the University of Bergen, in particular Niels Bo Jensen, for carrying out measurements and processing the data with the TCS. Giorgia Confalonieri and Alessandro Pavese, are also warmly thanked for the XRD analyses. The authors are extremely grateful to Jasmin Raymond for the use of the GHP in the Geothermal Open Lab at the Institut national de la recherche scientifique of Québec, Canada.

\section{Author Contributions}

564 N.G. collected the samples and took care of the samples preparation for OS and TLS, measurements and data processing of thermal conductivity with TLS; he also performed P-wave analyses and processed the data. J.C. prepared the samples, carried out analyses and processed the data of TDB and GHP; she also took care of XRD processing and density analyses. N.G. and J.C. wrote together the original draft paper, finalizing figures and tables. W.H.W. and G.M. conceptualized the original idea of the study, and together with M.V. advised on the rigorous experimental analyses and revised the manuscript.

\section{References}

Alishaev MG, Abdulagatov IM, Abdulagatova ZZ (2012) Effective thermal conductivity of fluidsaturated rocks. Experiment and modeling. Eng Geol 135-136:24-39.

Al-Khafaji S, Purnell P (2016) Effect of coupling media on ultrasonic pulse velocity in concrete: a preliminary investigation. Int J Civ Env Eng 10:118-121.

Andolfsson T (2013) Analyses of thermal conductivity from mineral composition and analyses by use of Thermal Conductivity Scanner: A study of thermal properties in Scanian rock types. Dissertation, Lund University. 
ASTM C177 (2013) Standard test method for steady-state heat flux measurements and thermal transmission properties by means of the guarded-hot-plate apparatus. ASTM International, West Conshohocken, PA, doi: 10.1520/C0177-13.

ASTM D5334 (2014) Standard test method for determination of thermal conductivity of soil and soft rock by thermal needle probe procedure. ASTM International, West Conshohocken, PA, doi: 10.1520/D5334-14.

ASTM C518 (2017) Standard test method for steady-state thermal transmission properties by means of the heat flow meter apparatus. ASTM International, West Conshohocken, PA, doi: 10.1520/C0518-17.

ASTM D2845 (2008) Standard test method for laboratory determination of pulse velocities and ultrasonic elastic constants of rock. ASTM International, West Conshohocken, PA, doi: 10.1520/D2845-08.

Bristow KL, White RD, Kluitenberg GJ (1994) Comparison of single and dual probes for measuring soil thermal properties with transient heating. Austr J Soil Res 32:447-464.

Cabeza LF (2015) Advances in thermal energy storage systems - methods and applications. Woodhead Publishing, Cambridge, UK.

Čermák VL, Rybach L (1982) Thermal conductivity and specific heat of minerals and rocks. In: Angenheister $\mathrm{G}$ (ed) Numerical Data and Functional Relationships in Science and Technology, New Series, Group V (Geophysics and Space Research), Vol. 1a (Physical Properties of Rocks), Springer, Berlin, pp 305-343.

Clauser C, Huenges E (1995) Thermal conductivity of rocks and minerals. Rock physics \& phase relations: a handbook of physical constants, American Geophysical Union, pp 105-126.

Di Sipio E, Galgaro A, Destro E, Teza G, Chiesa S, Giaretta A, Manzella A (2014) Subsurface thermal conductivity assessment in Calabria (southern Italy): a regional case study. Env Earth Sci 72:1383-1401.

Eppelbaum L, Kutasov I, Pilchin A (2014) Thermal properties of rocks and density of fluids. In: Applied Geothermics. Springer, Berlin, pp 99-149.

Filla BJ (1997) A steady-state high-temperature apparatus for measuring thermal conductivity of ceramics. Rev Sci Ins 68(7):2822-2829.

Fossen H (1989) Geology of the Minor Bergen Arc, West Norway. Norg Geol Unders Bull, 416:47-62.

Fossen H, Ragnhildstveit J (2008) Berggrunnskart 1115 I, Scale 1:50.000, Norge Geol Unders.

Fuchs S, Schütz F, Förster HJ, Förster A (2013) Evaluation of common mixing models for calculating bulk thermal conductivity of sedimentary rocks: correction charts and new conversion equations. Geoth 47:40-52.

Giordano N, Chicco J, Bastesen E, Wheeler WH, Mandrone G (2017) Thermo-hydraulic characterization of a fractured shallow reservoir in Bergen (Norway) to improve the efficiency of a BHE field. European Geosciences Union, General Assembly, April 23-28, Wien, Austria, EGU2017-18581. 
Giordano N, Comina C, Mandrone G, Cagni A (2016) Borehole thermal energy storage (BTES). First results from the injection phase of a living lab built up in unsaturated alluvial deposits (Torino, IT). Ren En 86:993-1008.

IEEE Guide for Soil Thermal Resistivity Measurements (2003). IEEE Std 442-1981 1-16.

Kolderup CF, Kolderup NH (1940) Geology of the Bergen Arc System. Bergen Museums Skrifter, 20, $137 \mathrm{p}$.

Kukkonen IT, Peltoniemi S (1998) Relationships between thermal and other petrophysical properties of rocks in Finland. Phys Chem Earth 23(3):341-349.

Lund JW, Boyd TL (2015) Direct utilization of geothermal energy 2015 worldwide review. Proceedings World Geothermal Congress, n. 01000, April 19-25, Melbourne, Australia.

Merriman JD, Whittington AG, Hofmeister AM, Nabelek PI, Benn K (2013). Thermal transport properties of major Archean rock types to high temperature and implications for cratonic geotherms. Precambrian Res 233:358-372.

Miao SQ, Li HP, Chen G (2014). Temperature dependence of thermal diffusivity, specific heat capacity, and thermal conductivity for several types of rocks. J Therm Anal Calorim 115(2): 10571063.

Midttømme K, Ramstad RK, Müller J (2015) Geothermal energy - Country update for Norway. Proceedings World Geothermal Congress, n. 01071, April 19-25, Melbourne, Australia.

Mielke P, Bär K, Sass I (2017) Determining the relationship of thermal conductivity and compressional wave velocity of common rock types as a basis for reservoir characterization. J App Geophys 140:135-144.

Pasquale V, Verdoya M, Chiozzi P (2015) Measurements of rock thermal conductivity with a Transient Divided Bar. Geoth, 53:183-189.

Popov YA, Beardsmore G, Clauser C, Roy S (2016) ISRM Suggested methods for determining thermal properties of rocks from laboratory tests at atmospheric pressure. Rock Mechanics and Rock Engineering 49:4179-4207.

Popov YA, Pribnow DFC, Sass JH, Williams CF, Burkhardt H (1999) Characterization of rock thermal conductivity by high-resolution optical scanning. Geoth 28:253-276.

Ramstad RK, Midttømme K, Liebel TH, Frengstad BS, WIllemoes-Wissing B (2015) Thermal conductivity map of the Oslo region based on thermal diffusivity measurements of rock core samples. Bull Eng Geol Env 74:1275-1286.

Raymond J, Comeau F-A, Malo M, Blessent D, López Sánchez IJ (2017) The geothermal open laboratory: a free space to measure thermal and hydraulic properties of geological materials. IGCP636 Annual Meeting, Santiago de Chile, Chile, 1-3.

Yang H, Cui P, Fang Z, (2010) Vertical-borehole ground-coupled heat pumps: a review of models and systems. App En 87:16-27.

Zhao D, Quian X, Gu X, Ayub Jajjia S, Yang R (2016) Measurement techniques for thermal conductivity and interfacial thermal conductance of bulk and thin film materials. J Elect Pack 138(4):040802. 